\title{
MIDAS
}

Museus e estudos interdisciplinares

$11 \mid 2020$

Dossier temático: "Perspetivas sobre o museu eclético"

\section{Para além da Pintura. Alguns apontamentos sobre as outras coleções do conde Daupias}

Beyond painting. Some notes on Count Daupias' other art collections

\section{Ramiro A. Gonçalves}

\section{(2) OpenEdition \\ Journals}

Edição electrónica

URL: http://journals.openedition.org/midas/2032

DOI: $10.4000 /$ midas.2032

ISSN: 2182-9543

\section{Editora:}

Alice Semedo, Paulo Simões Rodrigues, Pedro Casaleiro, Raquel Henriques da Silva, Ana Carvalho

\section{Refêrencia eletrónica}

Ramiro A. Gonçalves, « Para além da Pintura. Alguns apontamentos sobre as outras coleções do conde Daupias », MIDAS [Online], 11 | 2020, posto online no dia 19 novembro 2020, consultado no dia 21 novembro 2020. URL : http://journals.openedition.org/midas/2032 ; DOI : https://doi.org/10.4000/ midas. 2032

Este documento foi criado de forma automática no dia 21 novembro 2020

\section{(i) 8 (2)

Midas is licensed under a Creative Commons Attribution-NonCommercial-ShareAlike 3.0 International License 


\title{
Para além da Pintura. Alguns apontamentos sobre as outras coleções do conde Daupias
}

Beyond painting. Some notes on Count Daupias' other art collections

\author{
Ramiro A. Gonçalves
}

\section{NOTA DO EDITOR}

Artigo recebido a 12.02.2019

Aprovado para publicação a 15.03.2020

Agradecimentos: Ana Daupias d'Alcochete e Nuno Daupias d'Alcochete; Raquel Henriques da Silva (Instituto de História da Arte, Universidade Nova de Lisboa); Hugo Xavier (Palácio Nacional da Pena); Anísio Franco, Celina Bastos, Conceição Borges de Sousa, Luís Montalvão, Luísa Penalva e Miguel Soromenho (Museu Nacional de Arte Antiga); Emília Ferreira e Maria de Aires Silveira (Museu Nacional de Arte Contemporânea - Museu do Chiado); Nuno Prates (Casa dos PatudosMuseu de Alpiarça).

\section{O conde de Daupias}

O franco-português Pedro Eugénio Daupias (1818-1900), $1 .^{\circ}$ visconde e $1 .^{\circ}$ conde de Daupias $^{1}$, nasceu em 1818 na cidade de Paris onde o pai, Bernardo Daupias (1781-1862), 1. o visconde e 1. o barão de Alcochete, era cônsul-geral de Portugal. Foi sua mãe Marie Vitória Laurent (1790-1880). ${ }^{2}$ Por volta de 1840, Pedro Daupias, bacharel pelo liceu Louis-le-Grand, veio para Lisboa. Naturalizou-se português e começou a trabalhar na administração das fábricas de tecidos, na zona de Alcântara, pertencentes à família (Ortigão 1882, 1). Em 1845, casou com Joana Pereira de Almeida (1822-1891). O casal teve duas filhas: Vitória Emília (1846-1876) e Júlia Eugénia (1854-1874). Em 1865, Vitória casou com Bernard Théodore Deffez (1834-1909), comerciante com atividade em 
Bordéus. Júlia casou, em 1873, com João Burnay (1843-1903). No ano seguinte ao casamento, a jovem faleceu. Dois anos depois, em 1876, morreu, em França, a filha mais velha do casal Daupias, deixando duas filhas órfãs: Joana Deffez (1867-1901) e Maria Júlia Deffez (1869-1959).

2 No meio da tragédia familiar, o colecionismo de objetos de arte tornava-se para Pedro Daupias uma distração do sofrimento pessoal. Podemos defini-lo como um colecionador sentimental e, justamente, o período de maior atividade colecionista decorreu entre 1874-1891. ${ }^{3}$ Sobre isto, as suas próprias palavras ao jornalista Rangel de Lima são elucidativas:

Creia, meu caro sr., que a consolação unica dos meus tristes dias são estes quadros.

Vivo com elles e quasi que só para elles. Passo horas esquecidas a comtemplal-os

[sic] e é quando a minha dôr sente algum allivio, quando a minha saudade abranda e

se suaviza um pouco. (Lima 1904, 2)

O sucesso com que administrou as empresas herdadas foi determinante na reunião de um conjunto de coleções de nível internacional. o núcleo de pintura, de todas as coleções reunidas, foi sem dúvida aquele ao qual o conde dedicou mais tempo e dinheiro. Obras de velhos mestres franceses, como Jean-Marc Nattier (1685-1766), JeanHonoré Fragonard (1732-1806), Jean-Baptiste Greuze (1725-1805), ou italianos, como é o caso de Giovanni Battista Tiepolo (1692-1770) ou de Giovanni Paolo Panini (1691-1765), estavam penduradas ao lado das de artistas contemporâneos como Jean-BaptisteCamille Corot (1796-1875), Constant Troyon (1810-1865), Giovanni Boldini (1842-1931) ou Jean-François Millet (1814-1875), entre outros. Sendo, atualmente, o conjunto que mais atrai a atenção dos investigadores, as outras coleções não deixam de complementar a visão e o ambiente colecionista idealizado por Daupias.

\section{As outras coleções}

4 Para além da pintura, o núcleo de escultura moderna é, também, razoavelmente conhecido, uma vez que aparece descrito nos catálogos, com algum pormenor. Em contrapartida, o mesmo não acontece com as artes decorativas (cerâmica, têxteis, mobiliário, ourivesaria e diversos) as quais, excetuando algumas peças de relevo, são enumeradas sumariamente. No arquivo de Nuno Daupias d'Alcochete, generosamente disponibilizado pela filha, Ana Daupias d'Alcochete, encontramos alguns recibos relativos a compras de objetos de artes decorativas pelo conde Daupias catalogadas pelo colecionador como "Object d'art" em anotações nos recibos dos artefactos. ${ }^{4}$ As peças de uso quotidiano, no âmbito familiar, constituem, por seu lado, um núcleo autónomo a estudar futuramente. Assim, através das descrições da Galeria do conde Daupias feitas por alguns visitantes e da ênfase dada em vários catálogos (1882; 1882a; 1894; 1910; 1910a) - focando uma ou outra peça, propomo-nos fazer uma caracterização sumária (qualitativa e, quando possível, quantitativa) de cada um dos diferentes núcleos (número aproximado de peças; categoria; subcategorias); e quando dispusermos de informações mais extensas, far-se-á um comentário de obra.

O núcleo de escultura reunido pelo conde era constituído por cerca de 90 obras. Incluía peças de mármore, bronze e terracota, de que são exemplo duas pequenas placas em barro cozido do escultor sevilhano Antonio de las Peñas y León (1815-1886). ${ }^{5}$ Segundo o catálogo $(1882,71-74)$ organizado pelo conde da sua coleção, em 1882, pelo menos 12 peças eram de artistas contemporâneos: Angelo Cuglierero (1850-1903), François- 
Frédéric Steenackers (1830-1911), Albert-Ernest Carrier-Belleuse (1824-1887), Prosper d'Epinay (1836-1914), Francisque-Joseph Duret (1804-1865), Antoine-Louis Barye (1795-1875), Giovanni Spertini (1821-1895) e Giani de Côme (?) ou Paul Comolera (1818-1897). As compras do conde continuaram para além de 1882. Através dos catálogos de leilões podemos identificar peças francesas e italianas dos séculos XVIII e XIX, como, por exemplo, o grupo escultórico Cupido e Ninfa (fig. 1) em bronze fundido pelos Thiébaut Freres, segundo modelo original de Alexandre Falguière (1831-1900), e que atualmente integra o acervo do Museu Nacional de Arte Antiga (inv. $386 \mathrm{Met}$ ).

Exceção ao cenário traçado é o conjunto de três obras da autoria do português José Simões de Almeida (1844-1926), conhecido como Simões de Almeida (Tio), representado na coleção com um busto de uma Varina e com os bustos do casal Daupias, estes, atualmente propriedade do Museu Nacional de Arte Contemporânea-Museu do Chiado (inv. 666 e 667).

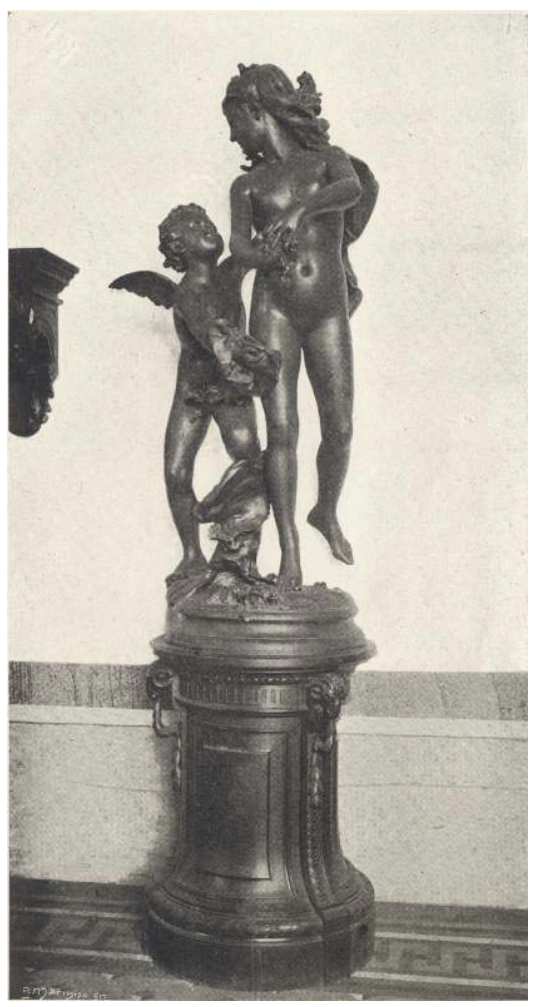

Fig. 1 - Cupido e Ninfa. Fundição Thibault Freres, segundo modelo de Jean-Alexandre-Joseph Falguière (1831-1900). Escultura em bronze: aprox. 165 cm; Base: aprox. 60 cm, Prov. Legado, Manuel da Graça Costa e Silva, 1950, Museu Nacional de Arte Antiga, inv. 386 Met

Imagem publicada no Catalogo de Quadros e Objectos d'arte e Mobiliario Existentes nas Galerias do Palacete [...] (1910) @ Direitos reservados

7 Uma das peças escultóricas mais interessante era um «Medalhão em faiança, com o busto de um imperador romano, cercado de uma grinalda de folhas e fructos de variado colorido. Obra de Lucca della Robbia. Seculo XVI» (Catálogo 1882a, 203), peça de que se perdeu o rasto pois não surge mencionada nos sucessivos leilões. ${ }^{6}$

8 Na coleção Daupias, o núcleo de cerâmica era numeroso mas, como referido, importa tentar separar as peças de coleção (c. 730 peças) dos objetos de uso quotidiano (c. 1500 peças), tarefa difícil, pois a muitos dos objetos colecionados era dada, muitas vezes, utilidade prática: por exemplo, alguns dos jarrões e das jarras dispostos na Galeria eram, frequentemente, «ornados de flôres vivas» (Ortigão 1882, 1). 
O conjunto das cerâmicas era composto por faiança e porcelana. A faiança dividia-se por subcategorias, de acordo com os respetivos centros de produção: portuguesa (Rato e Caldas da Rainha) ${ }^{7}$ e peças de autor como António Luís de Jesus (at. 1877-1905) ${ }^{8}$ ou Wenceslau Cifka (1811-1883) ${ }^{9}$, espanhola, francesa (Sceaux, Lorraine, Midi, Alsacienne, Bordeaux), sueca (Marieberg), alemã (Höchst e Kiel), holandesa (Delft), inglesa (Derby) italiana (Castelli, Urbino, Pesaro e Veneza). Na porcelana podemos elencar subcategorias, igualmente tendo em conta os centros de produção: alemã (Meissen, Frankenthal, Saxe, Nymphenburg, Höchst, Furstenberg, Berlim), austríaca (Viena), francesa (Sèvres), inglesa (Wedgwood), portuguesa (Vista Alegre), italiana (Capodimonte), indiana, persa, chinesa e japonesa. A variedade cronológica e tipológica de peças é grande, incluindo pequenas estatuetas decorativas (um conjunto de 42 peças foi vendida em Paris [Catálogo 1894]), cães-de-fó, canudos para bengalas, jarras, potes, talhas, jarrões, pratos, fruteiros, perfumadores, escarradores, bancos de jardim, frascos de rapé, "pequena commoda em louça, com quatro gavetinhas» (Catálogo 1910, 66), medalhões e estatuetas em biscuit ou em faiança, e até um aquário. Nos objetos quotidianos podemos incluir uma grande quantidade de serviços de jantar, sobremesa, café e chá.

O conde comprou por vezes em leilão coleções inteiras, como foi o caso da «rica e valiosa colleção de peças etruscas» adquiridas na venda dos bens de Francisco de Zea Bermudez (1821-1883) por “6:457\$500 réis" (Diário Illustrado, 19 de abril de 1883, n.․ 3573, p. 3).$^{10}$ A proveniência era irrepreensível, com pelo menos uma peça a figurar na obra de referência para a cerâmica clássica de Friedrich Wilhelm Eduard Gerhard (1795-1867) (cf. Gerhard 1843), pois Zea Bermudez, que havia sido diplomata em Itália, tinha adquirido as peças diretamente nas escavações de Pompeia (Mariz 2018, 282-283). Em 1891, o conjunto seria apreciado pelo francês Alexandre Boutroue (1846-1899), que o mencionou no relatório publicado em 1893, chamando a atenção para o «vase catalogué $n^{\circ} 7$, publié en 1843 par Gerhard à la planche 95-96 de ses Auserlesene Vasenbilder; et le $n^{\circ} 13$, qui est un des beaux produits de la céramique peinte du $V^{\circ}$ siècle avant $J-C_{»}$ (Boutroue 1893, 5). A importância da coleção fez com que Boutroue oferecesse um conjunto de 12 fotografias dela à Bibliothèque de l'École des Beaux-Arts de Paris (Boutroue 1893, 5). Segundo o 4. conde de Mafra, visitante assíduo da casa, a "valiosa coleção de vasos etruscos» era guardada e exposta num «grande armario hollandez envidraçado» (Breyner 1934, 63). O conjunto não figura em nenhum catálogo de leilão, pelo que colocamos a hipótese de ter sido transacionada em venda privada. Pelo menos dois vasos gregos "dito etruscos" foram oferecidos para venda no Rio de Janeiro, em 1913, por José dos Santos Libório (1850-1923) (Mariz 2018, 282-283).

11 A coleção de têxteis era composta de tapeçarias, tapetes, colchas, paramentos litúrgicos, toalhas, rolos de tecido, entre outros. Revestia-se de especial importância pois o conde fizera a sua colossal fortuna graças à industrial têxtil. Na coleção de têxteis encontramos um núcleo significativo de colchas de fabrico indiano (54 peças) e espanhol (74 peças), passando pelos tecidos que integravam o mobiliário dos salões. Algumas das colchas da Índia poderão ser atualmente consideradas como «indoportuguesas», correspondendo a um verdadeiro mostruário de técnicas de bordado, na maioria de seda ou cetim, «bordada a matiz e ouro», «bordada a ouro» ou «bordada a torsal». As espanholas, maioritariamente em linho, eram «bordadas a seda frouxa» (Catálogo 1910). 

Triunfo de Baco, segundo cartão de François Boucher (1703-1770), era uma das peças que mais impressionava. O 4. conde de Mafra cita-a também nas suas memórias (Breyner 1934, 50) e uma repórter, R.M., que visitou a galeria em 1886, deslumbrou-se na sua presença: «the most prominent, as size, is the large Gobelin tapestry» -, que estava localizada na «sala Azul». A peça era de excelente qualidade e mantinha-se em bom estado de conservação - «is certified to be 150 years old, but is as bright in color as if it had left the loom». Nas palavras da jornalista R.M., era aliás neste compartimento que se encontravam «some of the most beautiful specimens of art in all its branches» (M. 1886, 3).

A coleção de mobiliário dispersa pela residência e galerias do conde Daupias não se limitava a peças de produção europeia, contando-se também, pelo menos, quatro contadores de origem indo-portuguesa. ${ }^{11} \mathrm{~A}$ muitas destas peças continuava a dar-se um uso utilitário, pelo que encontramos grandes lotes de móveis de assento - cadeiras, sofás, divãs ou fauteuils -, compreensíveis pelos frequentes saraus dados na Galeria, em grande variedade de madeiras e técnicas (xarão, embutidos, tremidos), com assento de palhinha ou estofados. Como exemplo, Thomaz de Mello Breyner cita dois conjuntos de mobília de sala, na «sala amarela» e outro da «sala azul» da residência Daupias, adquiridos «em Lisbôa no leilão do Palacio do Marquez de Penafiel» ${ }^{12}$ «ou um espelho enorme» proveniente do «palácio Ribeira Grande á Junqueira» que ostentava no topo o «escudo da nobre família, seguro por dois lobos marinhos» (Breyner 1934, 49-50) (fig. 2).

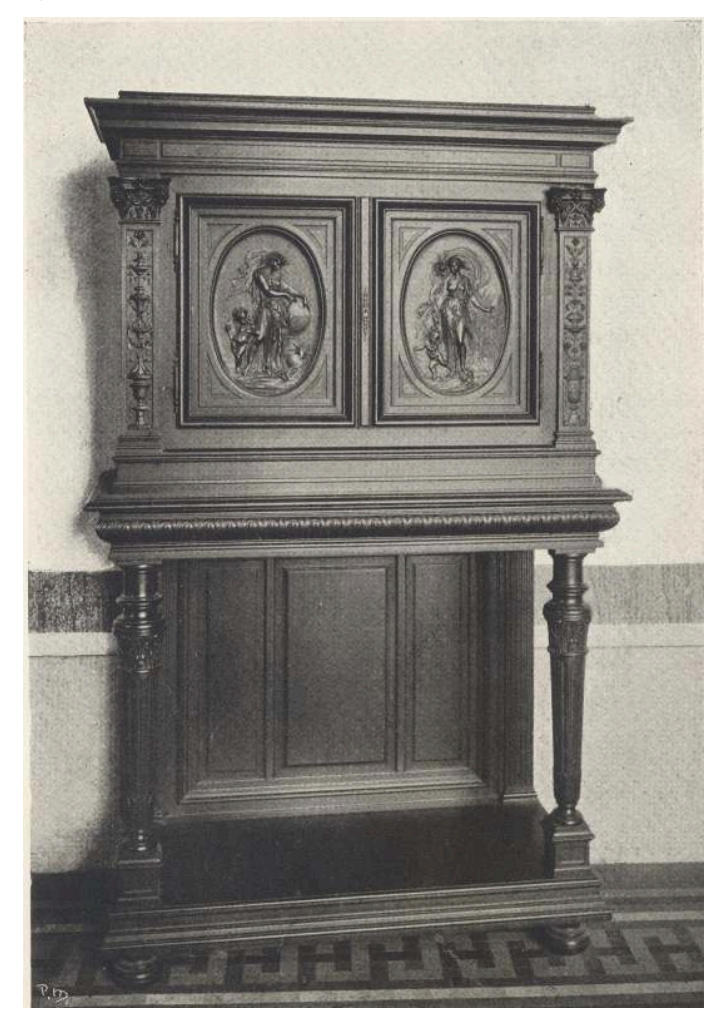

Fig. 2 - «Lote 1121 - Dois armarios pretos em dois corpos, com duas portas, com medalhões» Imagem publicada no Catalogo de Quadros e Objectos d'Arte e Mobiliario Existentes nas Galerias do Palacete [...] (1910) @ C Direitos reservados

Em termos estilísticos, imperavam o mobiliário português, os móveis Império e Boule. Nas memórias do 4. conde de Mafra são referidas outras importantes peças como «dois grandes armários holandeses», muito apreciados pelo autor, que estavam no primeiro 
patamar da residência (Breyner 1934, 46). Mas também podemos mencionar o contador italiano com embutidos de pedras duras nas gavetas (fig. 3) que atualmente se encontra exposto no Palácio Nacional de Sintra (PNS3054).

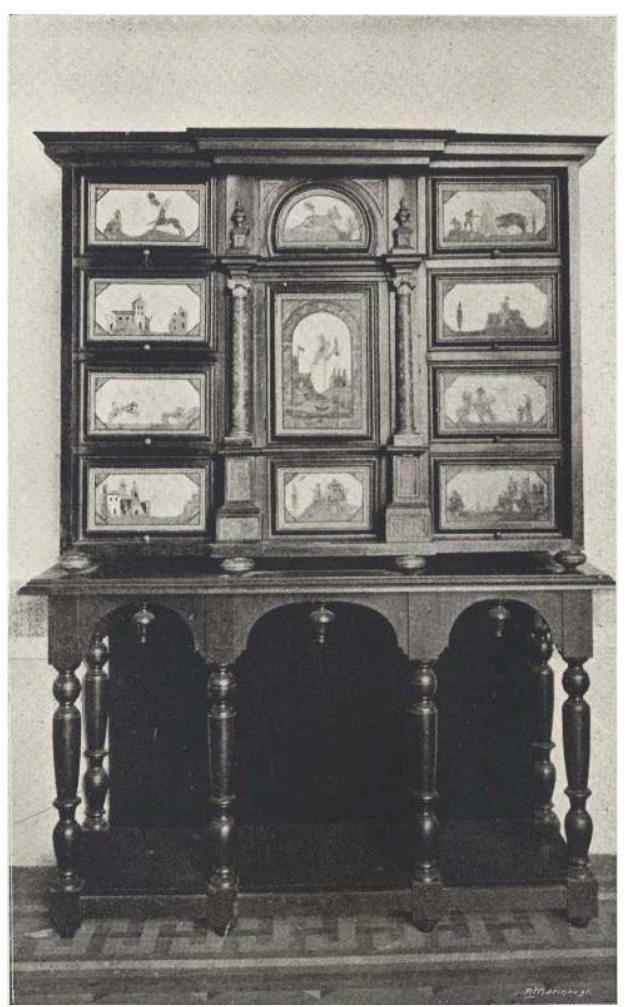

Fig. 3 - Contador século XVIII-XIX, Itália? Madeira, pedras duras, metal, pigmentos. Contador: alt. $100,5 \mathrm{~cm} \times$ larg. $133 \mathrm{~cm} \times$ prof. $45 \mathrm{~cm}$. Base: alt. $80,5 \mathrm{~cm} \times$ larg. $135 \mathrm{~cm} \times$ prof. $52 \mathrm{~cm}$. Palácio Nacional de Sintra, inv. PNS3054

Imagem publicada no Catalogo de Quadros e Objectos d'arte e Mobiliario Existentes nas Galerias do Palacete [...] (1910) @ D Direitos reservados

Pela sua singularidade, merece atenção uma cadeira de provável fabrico nacional exposta na Exposição de Arte Ornamental Portugueza e Espanhola ${ }^{13}$, realizada em Lisboa, em 1882, com a seguinte descrição:

Cadeira de nogueira, com o assento e costas de couro lavrado e seguro com pregos amarellos; os pés terminam em fórma de garras, e tem vários ornatos com aves, e no centro um medalhão representando Venus sobre as ondas dentro de uma concha e amparada por duas sereias. Seculo XVIII. [Sala L/cat. 185 (Catálogo 1882a, 238)]

Exemplar em destaque na coleção de mobiliário, surge aqui como representação de um gosto muito cultivado pelo mobiliário português no colecionismo nacional que Daupias certamente conhecia, mas não admirava a ponto de adquirir peças em grande número. Foi a única peça de mobiliário do conde presente na exposição de 1882.

O núcleo de ourivesaria divide-se em três categorias: religiosa (alfaias litúrgicas) ${ }^{14}$; civil ou de aparato (salvas); e utilitária (serviços de mesa). A origem das peças era variada, convivendo peças de fabrico nacional com outras de origens diversas (alemã, francesa, italiana). Apenas encontramos menções da prataria civil através da reportagem de Rangel de Lima (1875), no catálogo da Exposição de Arte Ornamental Portugueza e Espanhola e no Catálogo de 1894. Dois exemplares de salvas ganham destaque. A primeira é uma «Salva de prata dourada. A parte central é muito levantada e tem no cimo um brazão com seis arruellas. A ornamentação representa folhagens, monstros, cavalleiros, reis, 
pagens, etc. Diametro 0m,30» [Sala M/cat. 194 (Catálogo 1882a, 24)]. Numa fase posterior, esta peça ${ }^{15}$ seria transacionada no leilão de 1894 por 2.500 francos.

A segunda peça que iremos referir também esteve presente na mostra de 1882. Trata-se igualmente de uma salva assim descrita:

Prato relevado, cuja ornamentação consiste principalmente em grupos de guerreiros a pé e a cavallo. Os grupos são separados por cariatides. Reproducção em prata do original, obra do seculo XVI, que pertenceu á casa de Valladares e hoje á de Rotschild. Diametro 0m,48. [Sala M/Cat. 99, Catálogo (1882a, 12)]

Esta peça terá sido observada por Rangel de Lima, em 1875, na visita que fez à galeria do conde: «um prato magnifico de prata doirada, com figuras cinzeadas, representando uma batalha do tempo dos romanos». ${ }^{16}$ Mais uma vez o gosto eclético de Pedro Daupias está em sintonia com os padrões de gosto do colecionismo nacional. Contudo, as suas preocupações não se limitavam à aquisição de peças, incluindo igualmente preocupações expositivas na sua apresentação. Foi o caso da mencionada salva, que assentava «sobre um plintho feito de proposito para o expor», onde o repórter a pode admirar (Lima 1875, 3).

o último conjunto a abordado é genericamente designado por "diversos". A função deste grupo é abarcar um conjunto variado de tipologias, tanto de materiais como de objetos: metais, esmaltes de Limoges, relógios, leques, pequenas esculturas em madeiras ou marfins e outros. Em móveis-vitrinas estavam guardados preciosos bibelôs, leques, estatuetas em marfim ou em dente de cavalo-marinho, pequenas garrafas em diversos materiais, ou pequenos objetos de coleção como caixas de rapé, cigarreiras ou cartoneiras. Pelas salas podiam encontrar-se relógios e peças decorativas em bronze ornamentando mesas, cómodas, tremós ou consolas.

Das coleções reunidas neste conjunto ganha destaque o grupo de cinco placas de esmalte de Limoges: Enterro do Senhor; Jesus em Casa de Annaz; Jesus no Horto; Pilatos lavando as mãos; e Flagelação de Cristo -, adquiridas em Paris, em 1877, e cedidas para figurarem na exposição Exposição de Arte Ornamental Portugueza e Espanhola, em 1882. 0 conjunto despertou a atenção de investigadores nacionais e estrangeiros. $O$ português Joaquim de Vasconcelos (1849-1936) fez um breve comentário às peças na sua obra História da Ourivesaria e Joalheria Portuguesa, Sacra e Profana (Santos 2019, 54). E investigadores estrangeiros, como o crítico Charles Yriarte (1832-1898), o esmaltador Louis Bourdery (1852-1901) e o colecionador Emile Lachenaud (1835-1923), enviaram cartas com pedido de informações sobre as placas com temas da Paixão de Cristo ao conde Daupias (Santos 2019, 42). Todavia, a sua coleção de esmaltes era abrangente em termos de cronologia e de tipologias, desde um cofre do século XIII formado por placas de esmaltes a um par de pequenos vasos obcónicos do século XVII.

No leilão de 1894, a peça com esmaltes mais valorizada pelo mercado foi um «Plat ovale en émail peint par Martial Reymon [act. 1602-1603], Limoges, fin du XVIe siècle: le génie de la guerre, debout, drapé à l'antique, une torche à de main; marli orné d'animaux, de mascarons et de fleurs; sur le revers, une figure de Minerve» arrematado por 1,520 francos (lote 209, Catálogo 1894, 39). Esta peça encontra-se atualmente na The Frick Collection (inv. 1916.4.30) (fig. 4). 


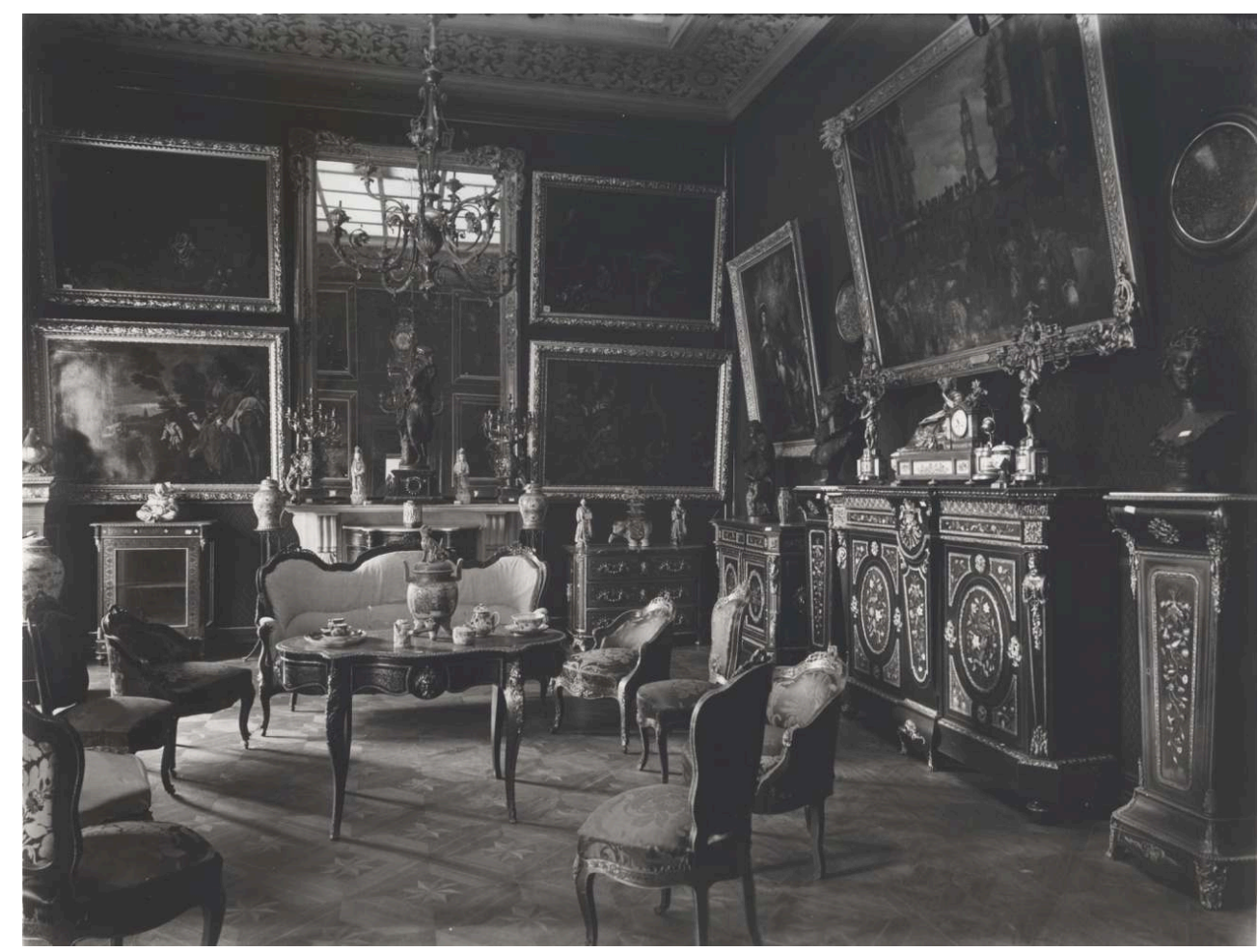

Fig. 4 - «Sala sétima»

Imagem publicada no Catalogo de Quadros e Objectos d'arte e Mobiliario Existentes nas Galerias do Palacete [...] (1910) @ Direitos reservados

\section{Da exposição à dispersão das coleções}

Até 1884 , do roteiro turístico de Lisboa para os amantes das belas artes constavam as seguintes galerias de pintura: a Galeria de Pintura do Real Paço da Ajuda ${ }^{17}$, o Museu da Academia de Bellas Artes ${ }^{18} \mathrm{e}$, por fim, a Galerie Pedre Daupias.

A presença de obras de mestres modernos como Corot, Troyon, Boldini ou Millet na galeria do conde terá levado Ramalho Ortigão a afirmar, em 1882:

A sua galeria de quadros e de objectos d'arte é uma das primeiras do mundo. Em Lisboa onde, graças à incúria administrativa e à ignorancia dos nossos governos, não existe ainda um museu nacional, a Galeria Daupias é a única escola pratica de Bellas Artes, é a única instituição esthetica. (Ortigão 1882,1)

O "musée Daupias" ("La Collection Daupias a Lisbonne" 1890, 155-157) surgia como um complemento importante na oferta das belas artes disponibilizadas na capital. A Galeria do conde Daupias era considerada, pelo menos desde 1877, ponto de paragem para nacionais e estrangeiros na capital, mediante solicitação prévia: «O visconde de Daupias facultava, aos domingos principalmente, a entrada na sua vasta galeria, aos visitantes, tanto nacionaes como estrangeiros» (Keil 1905, 13). O espaço expositivo destacava-se pelas características museológicas inovadoras como o uso de iluminação zenital aplicadas a uma galeria particular. Todavia evidencia-se por estar insolitamente implantado no meio de um complexo fabril e estando acessível aos operários, como revela a seguinte descrição:

O palácio Daupias situado á beira do Tejo está contiguo das importantes installações de uma fabrica de fiação e tecidos, fundada e explorada por este distincto industrial e que dá que fazer a centenares de operarios de ambos os sexos. Palacio, jardins, 
oficinas, machinas como que todo aquelle complexo de actividade forma um pequeno mas grandioso bairro hecterogeneo e originalíssimo. (Diario de Pernambuco, 25 de fevereiro de 1887, p. 2)

Outra forma de visitar a Galeria era através de convite para as soirées musicais que aí tinham lugar; os convivas podiam nessa altura conhecer as coleções pois «tanto o conde como a condessa forneciam amavelmente aos seus convidados as mais minuciosas explicações» (Lima 1904, 2). A pintura disputava a atenção dos visitantes com os outros objetos presentes: «As galerias são riquíssimas, não só em quadros, mas em jarras da Índia de Japão, Sévres, etc. É a primeira galeria de Portugal» (Diário Illustrado, 10 de fevereiro de 1877, n. 1465, 2). Ramalho Ortigão, em 1882, visitava as "preciosidades artísticas de toda a ordem: os moveis da Renascença esculpidos ou marchetados, as porcelanas de Sevres, da Saxonia, do Japão e da China, as majolicas italianas de Luca della Robia, os bronzes, os marfins, os esmaltes» (Ortigão 1882, 1).

A primeira descrição da Galeria Daupias data de 1875. O jornalista Rangel de Lima, para além do destacar a coleção de pintura, não deixa de mencionar outros objetos: «Em contravenção ao uso seguido na maior parte das galerias, encontram-se na do sr. Daupias, além dos quadros que guarnecem as paredes, alguns objectos de subido valor» (Lima 1875, 3), com isto referindo-se às peças de artes decorativas.

28 Tal como na pintura, o colecionador investiu nestes objetos avultadas somas. Em 1905, Alfredo Keil ainda evocava a presença das artes decorativas na Galeria, onde se expunham:

[...] grandes peças de mobiliario nacional, antigo; faianças, joias, marfins $\mathrm{e}$ miniaturas; esculpturas e um sem numero de bibelots-termo francez agora adoptado para designar pequenos exemplares de porcellanas e de esculpturas de todo o genero, objectos esmaltados e cousas exquisitas difficeis de classificar. (Keil 1905, 13)

A única imagem sobrevivente de parte da Galeria que Daupias construiu, anexa à sua residência no meio das fábricas de lanifícios no Calvário, propositadamente para albergar as suas obras de arte, é datada de 1910 (fig. 5). Ao observá-la, relembramos as palavras de Rangel de Lima: «Dois bufetes magníficos estão ao meio da casa, e sobre elles algumas louças preciosas» (Lima 1875, 3). Todo o espaço disponível era aproveitado: em vários bufetes colocados no centro dos compartimentos expunham-se, entre outras peças, «tres chavenas de Sévres, em uma das quaes se veem primorosamente pintados, os retratos de Henrique IV e de duas princezas. É finíssima esta amostra dos famosos productos da celebre fabrica franceza», ou mesmo «os cantos da galeria» adornados com «Algumas talhas da índia de muito preço» (Lima 1875, 3). 


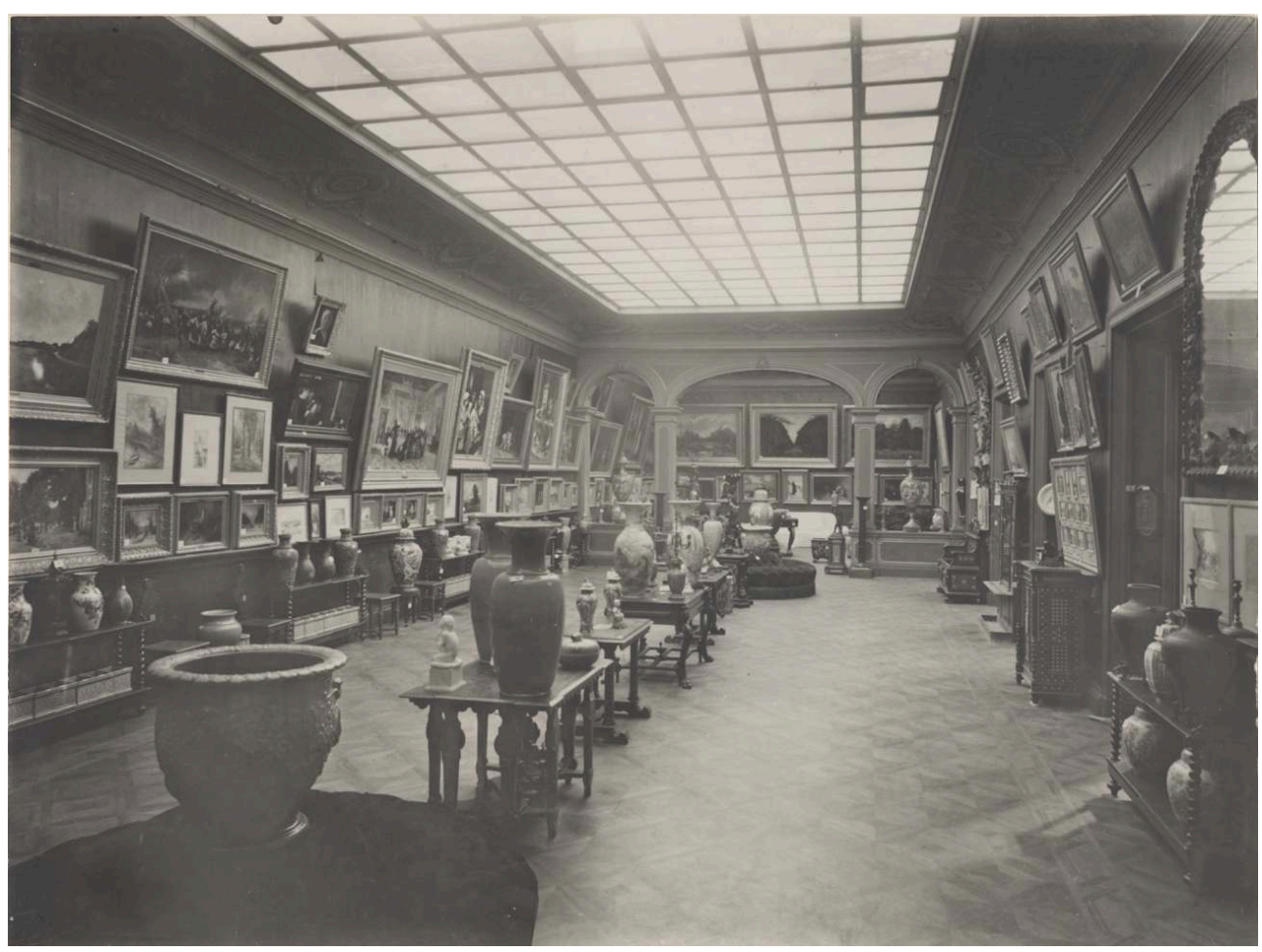

Fig. 5 - Galerie Pedre Daupias, 1910

Imagem publicada no Catalogo de Quadros e Objectos d'arte e Mobiliario Existentes nas Galerias do Palacete [...] (1910) @ C Direitos reservados

No início da década de 1890, a bancarrota nacional terá provavelmente afetado a Casa B. Daupias \& Co., mas não foi por esta razão que as melhores pinturas da coleção foram a leilão em 1892. A decisão decorreu do acordo amigável estabelecido entre o conde e as netas. Em 1891, havia falecido a condessa Daupias. No cartório notarial de Camilo José dos Santos, da Comarca de Lisboa, foi lavrada uma escritura, datada de 24 de março de 1892, onde era feita uma partilha amigável nas «proporções e nas condições estipuladas» ${ }^{19}$ de acordo com o testamento da falecida, ou seja, a divisão tripartida dos seus bens. Para facilitar as contas foi tomada a decisão de venda dos bens comuns do casal, que incluíam as coleções.

Em 1892 realizou-se, em Paris, o primeiro leilão de pinturas antigas e modernas da coleção Daupias. O evento, organizado pela Galerie George Petit, rendeu a soma extraordinária de «um milhão e duzentos mil francos-ouro» (França 1967, 414). o mercado leiloeiro parisiense era mais dinâmico para escoar coleções de qualidade, quer na área de pintura quer na área de artes decorativas. Em 1884, fora leiloada a importante coleção de cerâmica reunida por Francisco Ribeiro da Cunha ${ }^{20}$, no Hotel Drouot. $^{21}$

32 Em 1894, seguindo o exemplo da venda dos herdeiros de Ribeira da Cunha, o conde Daupias empreendeu um novo leilão de objetos em Paris. Na leiloeira Hotel Drouot, de 8 a 10 de novembro, foi levado à praça um conjunto de 277 lotes constituído por peças de artes decorativas: porcelanas de Saxe (estatuetas, serviço de jantar e outras peças), peças utilitárias em porcelana (Sèvres e China), faianças italianas, francesas e holandesas, objetos de vitrine, miniaturas, objetos variados, ourivesaria, esmaltes de Limoges, esculturas, pequenas esculturas em madeira e outras em marfim, relógios, bronzes, mobiliário francês e algumas têxteis (incluindo peças indo-portuguesas). 
Daupias ou Ribeiro da Cunha não foram os únicos a vender peças que haviam estado expostas na Exposição Retrospectiva de Arte Ornamental Portugueza e Hespanhola. Com a exposição, as peças passaram a ser conhecidas e cobiçadas pelos colecionadores e o seu valor de mercado subiu. Foi o caso da condessa d'Edla ${ }^{22}$ que, após a morte de D. Fernando de Saxe-Coburgo ${ }^{23}$ ocorrida em 1885 e da conclusão do processo de partilhas entre herdeiros em 1892, terá vendido algumas peças que estiveram na Exposição de Arte Ornamental, como foi o caso de um par de castiçais rococó em prata com marcas de Lisboa (século XVIII) decorados com motivos de chinoiserie: «Castiçal de prata. Ornamentação de arabescos. Na haste uma figura de phantasia. Seculo XVIII» ${ }^{24}$ que pertencem ao espólio da igreja de São Sebastião de Câmara de Lobos (Madeira).

Para além do leilão parisiense, em 1894, Pedro Daupias tentou fazer um leilão de pinturas em Lisboa, que foi suspenso por processo judicial movido por Eduardo Teixeira de Sampayo (1833-1906), advogado das netas do conde. A contestação advinha de ainda não terem recebido a sua parte dos lucros do leilão de 1892. O caso foi tornado público, tendo Teixeira de Sampayo publicado, a partir de 1895, algumas brochuras para esclarecer o processo movido pelas suas representantes.

5 O conde Daupias passava, entretanto, temporadas cada vez mais longas em Paris onde casou com Léa Roseyro Schwartz (1866-c. 1945), em 1895. Durante as estadias no estrangeiro, a administração das empresas foi confiada ao amigo Henri Burnay (1838-1909), 1.ํo conde de Burnay.

Agastado pelos sucessivos processos judicias, pela situação financeira, patrimonial e familiar, Pedro Daupias, após uma caminhada pelo complexo fabril em Alcântara, retirou-se para o seu quarto onde se suicidou com um tiro na cabeça, no dia 25 de janeiro de 1900.

37 Com a morte do avô, as netas moveram um processo judicial contra as firmas Henry Burnay \& Co. e Neuflize \& Co. pela gestão danosa da casa Casa B. Daupias \& Co. e pelo arresto dos bens feito pelas casas comerciais para pagamento de dívidas do conde. $\mathrm{O}$ imbróglio judicial só ficou resolvido passados cerca de dez anos sobre a morte trágica do conde, em favor da neta, Maria Júlia Deffez Burnay ${ }^{25}$. Assim, em 1910, todo o recheio da casa de Daupias assim como o remanescente da sua coleção, foi levado à praça. Através do catálogo e do respetivo suplemento obtemos uma visão geral do recheio da casa. De entre os 1730 lotes, encontramos pintura, escultura e artes decorativas assim como objetos do uso quotidiano como mobiliário, relógios, lustres, têxteis variados, livros e outras curiosidades que testemunham a opulência da casa e a adesão ao conforto moderno, como um telefone (Lote 1212) ou uma máquina para café (Lote 1276). O leilão seria um marco no panorama colecionista de Lisboa. Com vários anúncios publicados na imprensa portuguesa e não só, à capital portuguesa também acorreram compradores estrangeiros. Com início no dia 22 de janeiro de 1910, a venda durou vários dias, servindo para beneficiar outras coleções que se começavam a formar em Portugal.

\section{Conclusão}

38 Ao olhar para as coleções reunidas por Daupias, relembramos as palavras de Leo Tolstoi: «As famílias felizes parecem-se todas; as famílias infelizes são-no cada uma à sua maneira» $(1877,11)$. Na Galeria que idealizou na sua casa no meio das fábricas 
têxteis que possuía em Alcântara, o conde construiu um mausoléu à sua dor pela perda das filhas. $O$ seu mote, «trahit sua quemque volutas»" ${ }^{26}$ (cada qual tem o seu prazer que o arrasta), retirado das Éclogas de Virgílio, fornece-nos pistas sobre a motivação que descobriu através da arte para continuar a viver.

39 A grande paixão de Daupias era a pintura, mas foi um colecionador do seu tempo. Através da coleção de artes decorativas alinhou o seu gosto eclético com as práticas colecionistas em voga fora de Portugal e propagadas entre nós pelo rei D. Fernando II. Se o colecionador régio dispensou uma merecida atenção à produção nacional, o conde foi mais parco nas escolhas de peças nacionais. Certamente influenciado e influenciador, o conde conviveu com a elite colecionista da sua época em Lisboa e em Paris, tendo, muito provavelmente, incutido nos seus conterrâneos assim como em gerações de futuros praticantes, o gosto pelo bricabraque e a curiosidade por este "novo sport" (Keil 1905, 5-6).

A Galeria pensada de raiz, assim como a atenção à exibição e à conservação das peças levou a um pensamento museográfico invulgar para a sociedade portuguesa do seu tempo, adaptando e providenciando particulares soluções expositivas, neste caso um espaço para a exibição das obras de arte separado da área de habitação. Outras questões fizeram também parte das suas preocupações museográficas, prevendo, por exemplo, a iluminação zenital nas zonas de exposição. A organização de um catálogo da coleção de pintura e escultura de Escola Moderna e a conceção de dispositivos museográficos inovadores de modo a melhor poder usufruir das peças são outras tantas das inovações introduzidas por Daupias nas formas de apresentação e divulgação públicas da sua coleção.

41 Os inúmeros visitantes nacionais e estrangeiros que passaram pela Galeria Daupias, para além da atenção dada à pintura, sempre salientaram peças de artes decorativas de excecional qualidade presentes no espaço expositivo. Várias obras da coleção integraram importantes mostras, como a Exposição Retrospectiva de Arte Ornamental Portugueza e Hespanhola, organizada em Lisboa em 1882, ou a Exposição de Leques, patente em 1891 no recém-fundado Museu de Bellas Artes e Archeologia (atual Museu Nacional de Arte Antiga).

No leilão de objetos, em 1894, que teve lugar em Paris e que foi organizado pelo Hotel Drouot, ficou patente, como referimos, o interesse da clientela estrangeira pelas peças que haviam pertencido a Daupias.

Em suma, apesar da primazia dada à pintura, as restantes coleções contribuíram também para criar o ambiente único que se experimentava na Galeria Daupias. Era neste novo templo de homenagem às artes que o conde possivelmente se distraía da dor pela perda das filhas, encontrando a paz na meditação e contemplação artística. 


\section{BIBLIOGRAFIA}

"La Collection Daupias a Lisbonne." 1890. In L'Art Moderne. Bruxelas: Lebeer Hossmann, 18 de maio de 1890, 155-157. Disponível em: https://archive.org/details/3150452_4

Álvarez Cruz, Joaquín Manuel. 2007. "Nuevas Aportaciones al Catálogo del Barrista Antonio de las Peñas y León.” Laboratorio de Arte: Revista del Departamento de Historia del Arte, n.ำ 20: 378-389.

Boutroue, Alexandre. 1893. Rapport À M. Le Ministre De L'Instruction Publique et des Beaux-Arts sur une Mission Archéologique en Portugal et Dans le Sud de L'Espagne par M. Alexandre Boutroue. Paris: Ernest Leroux, Éditeur.

Breyner, Thomaz de Mello. 1930. Memórias do Professor Thomaz de Mello Breyner, $4^{\circ}$ Conde de Mafra, 1869-1880. Lisboa: Parceria António Maria Pereira.

Breyner, Thomaz de Mello. 1934. Memórias do Professor Thomaz de Mello Breyner, $4^{\circ}$ Conde de Mafra, 1880-1883. Lisboa: Oficina Grafica, L.DA.

Catálogo. 1882. Collection du V.te Daupias. École Moderne. Tableaux - Aquarelles - Sculptures. Lisboa: Lallement Frères Imprimeurs.

Catálogo. 1882a. Exposição Retrospectiva de Arte Ornamental Portugueza e Hespanhola. Lisboa: Imprensa Nacional.

Catálogo. 1882b. Exposição Retrospectiva de Arte Ornamental Portugueza e Hespanhola. Catalogo da Sala de Sua Magestade El-Rei o Senhor D. Fernando e da Excellentissima Senhora Condessa d'Edla - Sala F. [catálogo de exposição]. Lisboa: Imprensa Nacional.

Catálogo. 1884. COLLECTION FRANCISCO RIBEIRO DA CUNHA DE LISBONNE - CATALOGUE D'UNE COLLECTION IMPORTANTE D'OBJETS DE CÉRAMIQUE AVANT FIGURÉ EN PARTIE A l'EXposition rétrospective de Lisbonne, en 1882 DONT LA VENTE AURA LIEU HOTEL DROUOT. SALLE № 8 Les Jeudi 17, Vendredi 18 et Samedi 19 Avril 1884 A DEUX HEURES. Paris: Imprimerie Ve Renou, Maulde \& Cock.

Catálogo. 1894. CATALOGUE DES OBJETS D'ART ET D'AMEUBLEMENT Groupes, Statuettes, Services, Vases, en Ancienne Porcelaine de Saxe, Porcelaines de Sèvres, pâte tendre, d'Allemagne, de la Chine et du Japon Faïences Italiennes, Françaises, etc. BOITES, MINIATURES, OBJETS DE VITRINE, ORFÈVRERIE Émaux de Limoges TERRE CUITE PAR MARIN, ETC., MARBRES, CIRES, IVOIRES Pendules Louis XVI Bronzes et Meubles du XVIIIme siècle MEUBLE DE SALON EN TAPISSERIE DU TEMPS DE LOUIS XVI Etoffes Provenant de la Collection de M. le Comte DAUPIAS ET DONT LA VENTE AURA LIEU A PARIS HOTEL DROUOT, SALLES Nos 7 \& 8. Les Jeudi 8, Vendredi 9 et Samedi 10 Novembre 1894 A DEUX HEURES. Paris: Imp. de l'Art. E. Moreau et Cie.

Catálogo. 1910. Catalogo de Quadros e Objectos d'Arte e Mobiliario Existentes nas Galerias do Palacete que Pertenceu ao Fallecido Conde Daupias, e cujo Leilão se Effectuará no dia 22 de janeiro de 1910 e seguintes. Lisboa: Typ. do Annuario Commercial.

Catálogo. 1910a. Catalogo de Quadros e Objectos d'Arte e Mobiliario Existentes nas Galerias do Palacete que Pertenceu ao Fallecido Conde Daupias, e cujo Leilão se Effectuará no dia 22 de janeiro de 1910 e seguintes, Supplemento. Lisboa: Typ. do Annuario Commercial.

Catálogo. 1977. Enamels, Rugs and Silver in The Frick Collection. Volume VIII. Nova Iorque: The Frick Collection. 
Clode, Luiz Peter, e Manuel Juvenal Pita Ferreira. 1951. Património Artístico da Ilha da Madeira: Catálogo Ilustrado da Exposição de Ourivesaria Sacra. Convento de Santa Clara [catálogo de exposição]. Funchal: Junta Geral do Distrito Autónomo do Funchal.

Ferreira, Emília. 2017. Lisboa em Festa: A Exposição Retrospetiva de Arte Ornamental Portuguesa e Espanhola, 1882. Antecedentes de um Museu. Vol. 8. Coleção Estudos de Museus. Casal de Cambra: Caleidoscópio e Direção-Geral do Património Cultural.

França, José-Augusto França. 1967. A Arte em Portugal no Século XIX - Volume I. Vendas Novas: Bertrand Editora.

França, José-Augusto. 1981. Rafael Bordalo Pinheiro. Lisboa: Livraria Bertrand.

Gerhard, Eduard. 1843 Auserlesene Griechische Vasenbilder, hauptsächlich Etruskischen Fundorts (Band 2). Heroenbilder. Berlin.

Gonçalves, Ramiro A. (no prelo). “Dupias, Pedro Eugénio.” In Dicionário Quem é Quem na Museologia Portuguesa, coord. Emília Ferreira, Joana d'oliva Monteiro e Raquel Henriques da Silva, 140-142. Lisboa: Instituto de História da Arte da Faculdade de Ciências Sociais e Humanas da Universidade Nova de Lisboa.

Gonçalves, Ramiro A. (no prelo). "Memória da Presença de Esmaltes na Coleção do Conde Daupias." In De azul e de Ouro. Esmalte em Portugal da Época Medieval à Época Moderna, coord. Ana Paula Machado Santos. [catálogo de exposição]. Porto: Museu Nacional Soares dos Reis.

Grilo, Fernando. 2014. “Coleccionismo e Mercado de Arte em Portugal no Início do Século XX.” In Coleções de Arte em Portugal e Brasil nos séculos XIX e XX - Perfis e Trânsitos, coord. Maria João Neto e Marize Malta, 487-501. Casal de Cambra.

Keil, Alfredo. 1905. Collecções e Museus de Arte em Lisboa. Lisboa: Livraria Ferreira \& Oliveira.

Lima, Rangel de. 1875. “A Galeria de Quadros do sr. P. Daupias.” Diário Illustrado, 27 de janeiro de 1875, n. .827.

Lima, Rangel de. 1904. “Coisas do Seculo Passado. A Galeria Daupias (Continuação).” Correio do Brasil: Orgão Democrata, 31 de maio de 1904.

M., R. 1886. “A Woman's Letter from Portugal.” The American Register, 4 de dezembro de 1886.

Mariz, Vera. 2018. “José dos Santos Libório (1850-1923), um Notável Elo de Ligação entre os Mercados de Arte Português e Brasileiro." MODOS. Revista de História da Arte, vol. 2, n.o 2 (mai.): 271-291.

Matos, Maria Antónia Pinto de, e Maria de Sousa e Holstein Campilho, coord. 2001. Uma Família de Coleccionadores - Poder e Cultura. Antiga Colecção Palmela. Lisboa: Casa-Museu Dr. Anastácio Gonçalves/Instituto Português dos Museus.

Ortigão, Ramalho. 1882. "Visconde Daupias.” Diario Illustrado. Lisboa: 27 de fevereiro de 1882, n.. 3161.

Rattazzi, Maria. 1882. Portugal de Relance. Lisboa: Livraria Zeferino-Editora.

Robinson, John Charles, ed. 1881. Catalogue of the Special Loan Exhibition of Spanish and Portuguese Ornamental Art, South Kensington Museum. Londres: Chapman \& Hall, Limited.

Santos, Ana Paula Machado. 2019. Esmaltes de Limoges e Peninsulares em Portugal da Época Medieval à Época Moderna. Porto: Edições Afrontamento.

Santos, Luís Aguiar. 2001. “A Crise Financeira de 1891: Uma Tentativa de Explicação.” Análise Social, vol. XXXVI (158-159). 
Sousa, Francisco Clode de, dir. 2014. Madeira, do Atlântico aos Confins da Terra: 500 Anos: 1514-2014. Álbum da exposição. Funchal: Museu de Arte Sacra do Funchal, Diocese do Funchal.

Tolstoi, Leo. 1877 (2012). Ana Karenine. Tradução de António Pescada. 2. ed. Lisboa: Relógio d'Água.

Vairo, Giulia Rossi, coord. 2003. Henri Burnay de Banqueiro a Coleccionador. Lisboa: Instituto Português dos Museus, Casa-Museu Dr. Anastácio Gonçalves.

Xavier, Hugo, 2018. O Marquês de Sousa Holstein e a Formação da Galeria Nacional de Pintura da Academia de Belas Artes de Lisboa. Vol. 12. Coleção Estudos de Museus. Casal de Cambra: Caleidoscópio.

Xavier, Hugo. 2013. Galeria de Pintura no Real Paço da Ajuda. Lisboa: Imprensa Nacional-Casa da Moeda, Instituto de História da Arte.

\section{NOTAS}

1. Feito visconde em 1876 e elevado a conde em 1886. Oficialmente conde de Daupias, mas popularmente conhecido apenas como conde Daupias.

2. O casal Daupias pertencia à nova elite diplomática, representando a recém implementada monarquia liberal junto de Luís Filipe I, rei dos franceses. Numa das suas deslocações a Lisboa, a mãe do conde leva de Paris para «la Reina Doña Maria un magnifica cuna fabricada en esta corte com todos los objetos de envoltura aderentes» (Gaceta de Madrid, 21 de julho de 1837, n.o 963, p. 2). O berço era destinado ao futuro rei D. Pedro V de Portugal (1837-1861).

3. Neste ano é declarada a bancarrota do Estado português. Sobre a crise de 1891 veja-se Santos (2001).

4. Estas e outras informações inéditas sobre a aquisição de peças pelo conde Daupias aqui analisadas estão a ser estudadas no âmbito do doutoramento em História da Arte na Faculdade de Ciências Sociais e Humanas da Universidade Nova de Lisboa, no âmbito da tese registada sob o título: "Galerie Pedre Daupias. Uma Coleção de Pintura em Lisboa".

5. Uma das placas (lote: 235, in Catálogo 1910, 20) passou no início do século XXI no mercado leiloeiro espanhol (Álvarez Cruz 2007).

6. Através do confronto entre o catálogo da coleção de pintura da Escola Moderna organizado pelo conde em 1882 com os catálogos de leilões em que surgem pinturas (1892; 1894a; 1910; 1910a) encontramos algumas disparidades. Existem pinturas que terão sido transacionadas através de vendas privadas ou colocadas em outros leilões de várias proveniências. Também observamos esta situação nas artes decorativas.

7. 0 conde foi um dos acionistas/fundadores (França 1981, 503).

8. $O$ conde possuía um conjunto de cinco peças: lotes 248; 445 (atualmente pertence à Casa dos Patudos-Museu de Alpiarça: CPMA 84.370); 488 (Catálogo, 1910: 21; 36; 39). No Arquivo Nuno Daupias d'Alcochete existe um recibo de compra passado por António Luís de Jesus da "Fabrica de Louça" ao conde Daupias pela aquisição de "um Prato e amfora" pelo valor de $67 \$ 000$ réis no dia 10 de março de 1877. o lote foi integrado no núcleo "Object d'art" com o número de inventário 201. Sobre o conjunto de lotes comprados no leilão Daupias por José Relvas veja-se: Grilo (2014).

9. Lote 738 (Catálogo 1910, 62). A peça foi comprada, por $137 \$ 000$ réis, diretamente ao artista, a 25 de novembro de 1875, passando a estar inventariada no núcleo "Object d'art" com o número de inventário 207 conforme recibo guardado no Arquivo Nuno Daupias d'Alcochete.

10. A coleção não surge nos catálogos de leilões, pelo que terá sido transacionada privadamente. O negociante José dos Santos Libório (1850-1923) comercializou um lote de 30 peças 
“arqueológicas" no Rio de Janeiro entre 1912-3. A proveniência das peças é a coleção de Francisco de Zea Bermudez e coleção Daupias (Mariz 2018, 282-283).

11. Segundo Nuno Prates, no leilão Daupias de 1910, o colecionador José Relvas (1858-1929) comprou um par de contadores (CPMA 84.710 e CPMA 84.725) que se encontra atualmente exposto na "Sala dos Primitivos" na Casa dos Patudos-Museu de Alpiarça.

12. O leilão do recheio da residência da capital, Palácio do Correio-Mor, situado na rua de São Mamede, e das quintas com o respetivo recheio de que eram proprietários os marqueses de Penafiel, decorreu entre 15 de novembro de 3 de dezembro de 1875.

13. Sobre esta exposição veja-se Ferreira (2017).

14. Levantamos a hipótese da existência de um pequeno oratório de devoção privada guarnecido das respetivas alfaias litúrgicas na casa dos condes.

15. Lote 181 - «Plateau rond sur piédouche bas en argent doré à décor d'animaux chimériques, trophées et rinceaux en relief; l'ombilic très saillant présente des sujets historiques et un écusson armorié. Travail portugais du XVIe siècle» (Catálogo 1894, 35).

16. De acordo com Luísa Penalva, conservadora da coleção de ourivesaria e joalharia do Museu Nacional de Arte Antiga, poderá tratar-se da salva pertencente ao Metropolitan Museum of Art com o n.o de inventário 17.190.603.

17. Além da Galeria de Pintura, existia o Gabinete de Numismática/Museu das Antiguidades do Palácio da Ajuda, fundados pelo rei D. Luís. Foram inaugurados oficialmente em 1867, passando a estar abertas ao público gratuitamente ao domingo entre 1869 e 1879 . A partir de 1879, com a morte do segundo diretor da galeria, Tomás da Anunciação (1818-1879), as visitas continuaram a ser possíveis, mas apenas por marcação pelo menos até 1889, ano da morte do rei (Xavier 2013, 130-159).

18. O Museu da Academia de Bellas Artes ou Galeria Nacional de Pintura da Academia de Bellas Artes de Lisboa, iniciativa de marquês de Souza Holstein (1838-1878), irá abrir em 1868 até 1884, ano que o seu acervo transitou para o recém-fundado Museu de Bellas Artes e Archeologia (Xavier 2018, 222-260).

19. Arquivo Distrital de Setúbal - PT/ADSTB/JUD/TJCSXL/1/001/00078.

20. Francisco Ribeiro da Cunha foi um capitalista português do século XIX.

21. Parte das peças levadas a leilão haviam sido emprestadas para a exposição de 1882. O leilão contava com 435 lotes. O núcleo de porcelana composto de peças de fabrico francês (Sevres, Saint-Cloud, Chantily, Paris, Clignancourt e Niederwiller), fabrico alemão (Meissen, Ludwigsburg, Vienne, Berlin, Furstenberg, Hochst-Sur-Le-Mein e Nymphenburg), fabrico inglês (Chelsea, Worcester, Longport, Derby, Hanley, Burslem, Leeds e Stoke-Upon-Trent) e de outros centros de produção europeia como Buen-Retiro, Capo-Di-Monte, Copenhaga, Weesp, Limbach. O grupo de faianças era constituído por exemplares de Alcora, Delft, hispano-mouriscos, Marieberg, Rato, Savone e Talavera. E, por fim, naturalmente, o grupo de porcelana oriental, dividido em dois grupos: chinesa e japonesa.

22. Elise Hensler (1836-1929), 1. a condessa d'Edla, esposa morganática de D. Fernando II de Portugal.

23. D. Fernando II de Portugal (1816-1885) casou com a Rainha Dona Maria II de Portugal, tornando-se rei consorte. Após a morte da rainha, em 1869 casou em segundas núpcias com a condessa d'Edla.

24. (Catálogo 1882b: cat. 62 (com estampa, no 32) e 63). A comparação da gravura de um dos castiçais da condessa d'Edla com os castiçais que atualmente pertencem à igreja de São Sebastião de Câmara de Lobos (Madeira) é flagrante. Publicados pela primeira vez em 1951 (Clode e Pita, 1951: estampa 200), em 2014, Rui Carita formulou a hipótese de terem chegado à igreja madeirense por doação da família dos condes de Torre Bela. Em 2014, os referidos candelabros integraram a exposição Madeira, do Atlântico aos Confins da Terra: 500 Anos: 1514-2014 patente no Museu de Arte Sacra do Funchal (Sousa 2014, 135). No entanto, nunca foi estabelecida a sua 
possível relação com as peças expostas como provenientes da coleção de D. Fernando II de Portugal e da sua segunda esposa na exposição de 1882.

25. A neta mais velha do conde, Joana Deffez falecera em 1901.

26. Frase que aparece no selo de posse do conde Daupias colocado nas pinturas.

\section{RESUMOS}

Pedro Eugénio Daupias (1818-1900), 1. visconde e 1.ำ conde de Daupias, foi um dos mais importantes colecionadores em Portugal no último quartel do século XIX. Das várias coleções reunidas, a de pintura, pela excelência de algumas peças, é a que ganha maior destaque para a história da arte, estando alinhada com o gosto parisiense, embora as suas tendências ecléticas o tivessem levado a reunir todo o tipo de objetos artísticos: escultura, cerâmica, têxteis, mobiliário, ourivesaria, entre outros. No presente artigo faremos uma análise descritiva das diversas coleções, com referência a alguns objetos comentados pelos visitantes da Galeria do conde Daupias ou referidos, com descrições específicas, em catálogos de exposições ou leilões. O conde fez publicar em 1882 um catálogo dedicado à pintura e escultura modernas. A dispersão da coleção começa em 1892, quando uma seleção das melhores pinturas foi à praça em Paris. Em 1894, realizou-se um leilão dedicado às artes decorativas, novamente na capital francesa. E, dez anos após a morte do colecionador, em 1910, foi vendido num leilão em Lisboa o remanescente da coleção.

The French-Portuguese Pedro Eugénio Daupias (1818-1900), 1st Viscount and 1st Count Daupias, was one of the most important collectors in Portugal in the last quarter of the 19th century. Of the collections he gathered, the one on painting, for the excellent quality of some of its pieces, is the one that gets the attention from art historians, being aligned with the Parisian taste, even if his eclectic taste led him to collect all kinds of artistic objects: sculpture, ceramics, textiles, furniture, silverware and miscellaneous. In this paper we will make a brief descriptive analysis of his various collections, with reference to the objects commented by the Count Gallery visitors or referred to with specific descriptions in exhibitions or auction catalogues. In 1882, the Count published a catalogue dedicated to modern painting and sculpture. The dispersion of his collection began in 1892, when a selection of the best paintings was auctioned in Paris. In 1894, there was another auction dedicated to the decorative arts, again at the French capital. And ten years after the collector's death, in 1910, the remains of his collection were sold at yet another auction in Lisbon.

\section{ÍNDICE}

Palavras-chave: Conde Daupias, colecionismo privado, biografia, galeria do conde Daupias, ecletismo

Keywords: Count Daupias, private collecting, biography, eclecticism 


\section{AUTOR}

\section{RAMIRO A. GONÇALVES}

Doutorando em História da Arte na Faculdade de Ciências Sociais e Humanas da Universidade Nova de Lisboa (FCSH/UNL), com tese registada sob o título "Galerie Pedre Daupias. Uma Coleção de Pintura em Lisboa". Mestre em Comunicação, Culturas e Tecnologias pelo ISCTE - Instituto Universitário de Lisboa, pós-graduado em Mercado da Arte e Colecionismo (FCSH/UNL) e licenciado em Publicidade \& Marketing pela Escola Superior de Comunicação Social do Instituto Politécnico de Lisboa. Atualmente desempenha funções de técnico superior no Museu Nacional de Arte Antiga, afeto ao Departamento de Comunicação, assim como funções de assistente de conservador da coleção de pintura. Tem publicado artigos no âmbito da história do colecionismo e dos mercados da arte. É autor de textos para catálogos de exposições, tendo integrado o comissariado de exposições.

Museu Nacional de Arte Antiga, Rua das Janelas Verdes, 1249-017 Lisboa, Portugal, ramirogoncalves@mnaa.dgpc.pt 